\title{
Prediction of overall survival in patients with stage III and IV small cell lung cancer utilizing Primary tumor standardized uptake value on 18F-FDG PET/CT
}

Huynh Quang Huy ${ }^{1,2^{*}}$

*Correspondence: huyhq@pnt.edu.vn

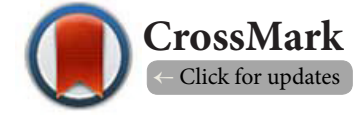

'Radiology Department, Pham Ngoc Thach University of Medicine, Vietnam.

${ }^{2}$ Radiology Department, HCMC Oncology Hospital, Vietnam.

\begin{abstract}
Objective: To evaluate ${ }^{18}$ FDG PET-CT for the prediction of overall survival in patients with small cell lung cancer after concurrent chemoradiotherapy.

Methods: Forty patients with pathologically proven stage III and III SCLC had FDG PET-CT scans before concurrent chemoradiotherapy. The maximum standardized uptake value $\left(\mathrm{SUV}_{\max }\right)$ of the primary lung lesion was calculated. The relationship between the $\mathrm{SUV}_{\text {max }}$ and the long-term survival was studied after concurrent chemoradiotherapy.

Results: A total of 40 patients were analyzed and follow-up in 3 years. The mean of survival time was 12.6 months (95\%CI:

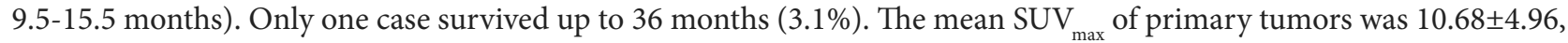

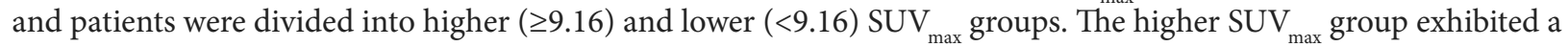
significantly worse OS compared with the lower $\mathrm{SUV}_{\max }$ group. Resession revealed a significant inverse relationship between $\mathrm{SUV}_{\max }$ and affected survival rate.

Conclusion: The prognosis of patients with SCLC who are diagnosed at advanced stage remains poor. 18FDG PET-CT is an effective method to predict the treatment outcomes of SCLC.
\end{abstract}

Keywords: Small cell lung cancer, prognosis, FDG-PET, survival

\section{Introduction}

Lung cancer is the major cause of death in the developing countries, with an incidence of about 65-70 new cases per 100.000 [1]. Lung cancer is histologically divided into 2 main types: small cell lung cancer (SCLC) and non-small cell lung cancer (NSCLC). SCLC is an aggressive disease that accounts for approximately $14 \%$ of all lung cancers. Unlike NSCLC, in which major advances have been made using targeted therapies, there are still no approved targeted drugs for SCLC. Consequently, the 5-year survival rate remains low at $<7 \%$ overall, and most patients survive for only 1 year or less after diagnosis [2-4]. [18F] fluoro-D-glucose positron-emission tomography ( ${ }^{18} \mathrm{~F}-\mathrm{FDG} \mathrm{PET} /$ CT) is widely used in lung cancer for staging, restaging and evaluation of the treatment response $[5,6]$. Multiple studies demonstrate that PET/CT is more sensitive and specific than PET alone in evaluating the lung cancer since it provides combined morphological and functional information of the tumour [7-10]. High accuracy of PET/CT has been observed in the early assessment of response to therapy, showing a close correlation between the reduction of tumour metabolic activity measured after a course of therapy and the clinical outcome of patients after the previewed cycles of therapy in patients in advanced stage $[11,12]$. However, patients with SCLC may experience a worse outcome than expected. Increased FDG uptake by lung cancer cells, measured as the maximum standardized uptake value $\left(\mathrm{SUV}_{\max }\right)$, has been reported to predict the biologic aggressiveness of both early and advanced NSCLC [13-16]; however, we do not find any prognostic studies for SCLC.

The aim of this study was to to evaluate the correlation between the maximum standardized uptake value (SUVmax) and overall survival (OS) in patients with small cell lung cancer after concurrent chemoradiotherapy (CCRT). 
Huynh Quang Huy, Medical Imaging and Radiology 2019,

\section{Material and Methods}

\section{Clinical data}

We prospectively analyzed the 18F-FDG PET-CT findings of 40 newly diagnosed SCLC patients between December 2010 and April 2019. They were selected according to the following criteria: (1) pathologically proven stage III and IV SCLC; (2) PET-CT was applied before any therapy. These patients were followed up for 3 years. Patients was enrolled by convenient sampling method. The patients were referred to Bach Mai Nuclear Medicine and Oncology Center for initial staging with PET-CT scan and treated with CCRT. The tumornode-metastasis (TNM) stage was determined according to the TNM $7^{\text {th }}$ edition [17]. TNM staging was obtained via information gathered through patient's chart including physical examination and total-body 18F-FDG PET/CT scan. Survival and death information were obtained from the hospitals databases and through phone calls to the patient families. The research proposal was approved by Institutional Review Board and Ethics Committee.

The inclusion criteria were histologically proven SCLC, glycaemia lower than $140 \mathrm{mg} / \mathrm{dl}$ at the time of the exam, availability of FDG-PET/CT and tumour size $>20 \mathrm{~mm}$ to minimize the under estimation of SUV. Exclusion criteria were as follows: (a) poor performance status; (b) diabetes (due to poor uptake of FDG); (c) pregnancy.

\section{Concurrent chemoradiation therapy}

All patients were treated with CCRT. Chemotherapy consisting of $1-4$ cycles of cisplatin $\left(20 \mathrm{mg} / \mathrm{m}^{2}\right)$ given on days $1-5$ (or days $1-3)$ and vinorelbine $\left(25 \mathrm{mg} / \mathrm{m}^{2}\right)$ given on days 1,8 , paclitaxel $\left(150 \mathrm{mg} / \mathrm{m}^{2} \mathrm{~d}\right)$ given on days 1,8 , or docetaxel $\left(75 \mathrm{mg} / \mathrm{m}^{2} \mathrm{~d}\right)$ given on days 1,8 . The first cycle of chemotherapy was applied the next day after the start of the radiotherapy. The second cycle of chemotherapy was applied 4 weeks after the first cycle. The radiotherapy was delivered by three-dimensional conformal radiotherapy technique. After setting up the patients in the vacuum bag, CT for treatment planning was performed in 4-mm slices, usually with intravenous contrast medium. Three-dimensional treatment planning was performed using the ADAC Pinnacle 7.4.

\section{FGD-PET-CT imaging}

$\mathrm{PET} / \mathrm{CT}$ imaging was performed with a median of 4 days (minimum 2 days, maximum 7 days) before starting treatment. Patients were asked to fast at least $6 \mathrm{~h}$ before the FDG-PET-CT scan. All patients had a glucose level below $180 \mathrm{mg} / \mathrm{dl}$ and were injected intravenously with $0.15-0.20 \mathrm{mCi} / \mathrm{kg}(7-12 \mathrm{mCi})$ FDG. At 45-60 min after the injection, data were acquired from the vertex to the upper thigh. Immediately after CT, a PET scan (PET/CT Biograph True Point - Siemens, Germany) was performed for about 25 min, with seven to eight bed positions and $3 \mathrm{~min} /$ position. PET images were reconstructed iteratively with CT data for attenuation correction, using an inline integrated Siemens Esoft Workstation system. Comput- erized tomography integrated positron emission tomography fusion images in transaxial, sagittal, and coronal planes were evaluated visually, and the SUVmax of lesions was obtained from transaxial images.

\section{Standardized uptake values}

The maximum SUV [SUVmax, the activity from the maximumvalued pixel within the tumour volume of interest (VOI); hereafter referred to as SUV] normalized to injected activity and patient body weight was calculated at approximately 60 min after tracer injection for each primary lesion and the chosen metastatic lesion with use of the following equation: $\mathrm{SUV}=$ maximum activity concentration in the VOI $[\mathrm{kBq} / \mathrm{ml}] /$ (injected dose $[\mathrm{MBq} / \mathrm{ml}] /$ patient body weight $[\mathrm{kg}]$ ). In patients with multiple metastatic lesions, the lesion with the largest diameter was chosen to prevent partial volume effects.

Tumors were classified into 2 groups by SUVmax base on the median of SUVmax: low-SUVmax $<$ median and highSUVmax $\geq$ median.

\section{Statistical analyses}

Continuous variables were summarized by mean and standard deviation, and categorical variables were summarized by frequency and percentage. Cox proportional hazard model was used to correlate continuous independent variables with survival. Survival functions of different populations were estimated by Kaplan-Meier estimator and compared by log-rank test. Multivariate Logistic resession was applied to assess the association between survival of patients and clinical factors. All analyses were performed by SPSS 20.0(Chicago, Illinois, USA).

\section{Results}

The study included 40 patients. Average age was $61.3 \pm 9.5$ years (range 38-81). Male/female ratio was 9.7/1. The SUVmax ranged from 2.36 to 20.40 (mean 10.68 \pm 4.96 ). The median SUVmax was 9.16, the low SUVmax group ranged from 2.36 to 9.13 (mean of $6.58 \pm 2.19$ ), and the high SUVmax group ranged from 9.20 to 20.40 (mean of 14.78 \pm 3.18 ).

Positron emission tomography-computed tomography scan results are listed in Table 1. A PET stage of IV was assigned to $46.9 \%$ of patients. The mean of tumor size and SUVmax in PET stage IV were significant higher than those in PET stage III respectively.

The mean of survival time after first performing PET/CT was 12.6 months ( $95 \% \mathrm{Cl}$ : 9.5-15.5 months). Only one case survived up to 36 months (3.1\%).

Table 1. Positron Emission Tomography-Computed Tomography Scan Results.

\begin{tabular}{llll}
\hline Variables & Stage III & Stage IV & P value \\
\hline $\mathrm{N}$ & 17 & 15 & \\
PET tumor size, mean $(\mathrm{cm})$ & $2.61 \pm 0.88$ & $7.88 \pm 1.96$ & $<0.01$ \\
SUVmax & $8.44 \pm 4.49$ & $13.21 \pm 4.29$ & 0.018 \\
\hline
\end{tabular}


Figure 1 shows survival stratified by PET stage. There was a significantly correlation between PET stage and survival $(p=$ 0.012), with survival decreasing as PET stage increased.

Although SUV is a continuous variable, we thought that estabishing "high-risk" and "low-risk" groups, based on SUV values, would act as a useful reference for clinicians. Dichotoization of SUV values was based on the median values. Patients who had an SUVmax higher than 9.16 had worse survival than patients with an SUVmax less than 9.16 ( $p<0.01$; Figures 2 and 3 ).

Some PET-CT images of patient with stage IV SCLC were showed in Figures 5-7.

Our analysis conducted controlling for the SUV max $_{\text {and other }}$ factors, the Multivariate Logistic Resession revealed a significant inverse relationship between SUV ${ }_{\text {max }}$ and affected survival

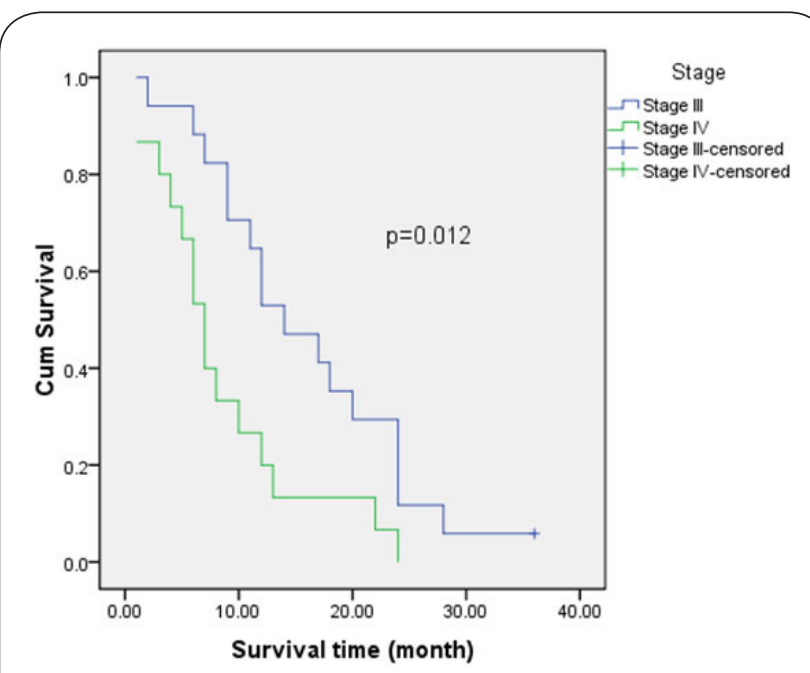

Figure 1. Positron emission tomography (PET) stage versus survival.

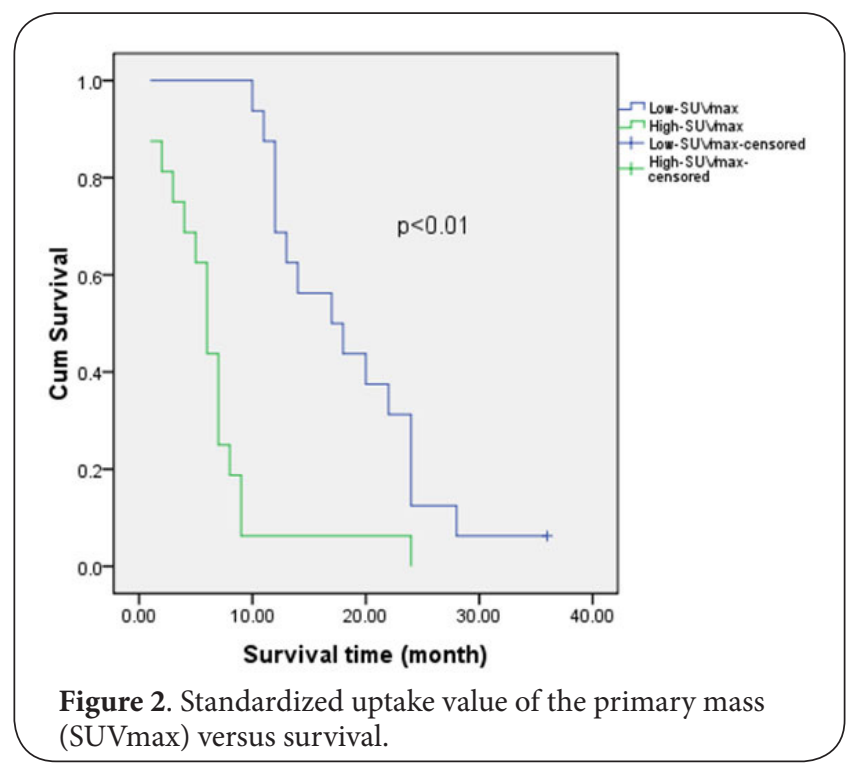

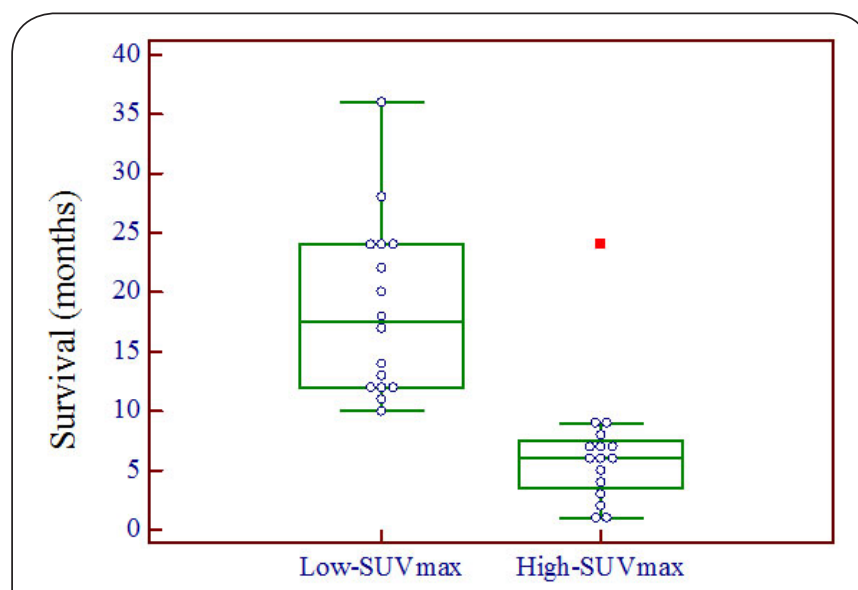

Figure 3. Association between primary mass (SUVmax) and survival.

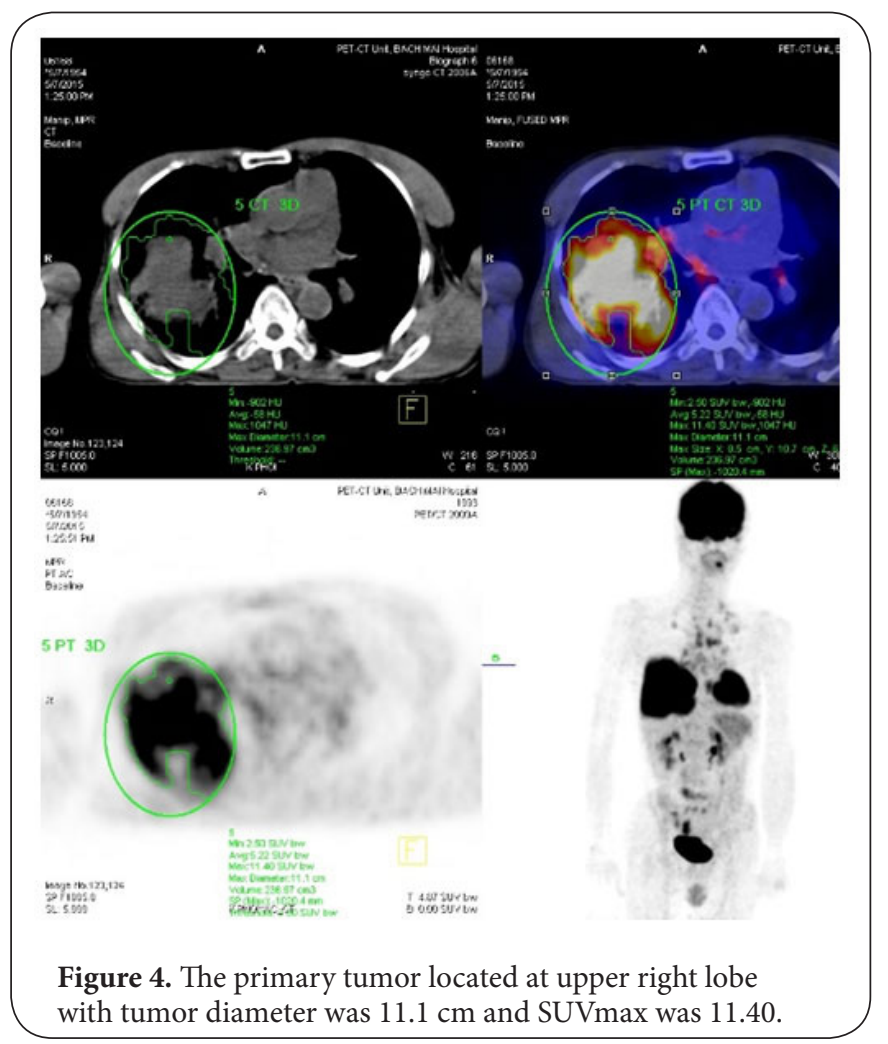

rate. The detailed data is shown in Table 2.

\section{Discussion}

Small cell lung cancer (SCLC) is a subtype of lung cancer with poor prognosis. It is estimated that nearly two million individuals are diagnosed as lung cancer every year, approximately $15 \%$ of which are SCLC [18]. SCLC is characterized by a rapid doubling time and the propensity for early dissemination. Chemotherapy remains the first line therapy for SCLC. Despite the initial response to chemotherapy, most tumors ultimately 

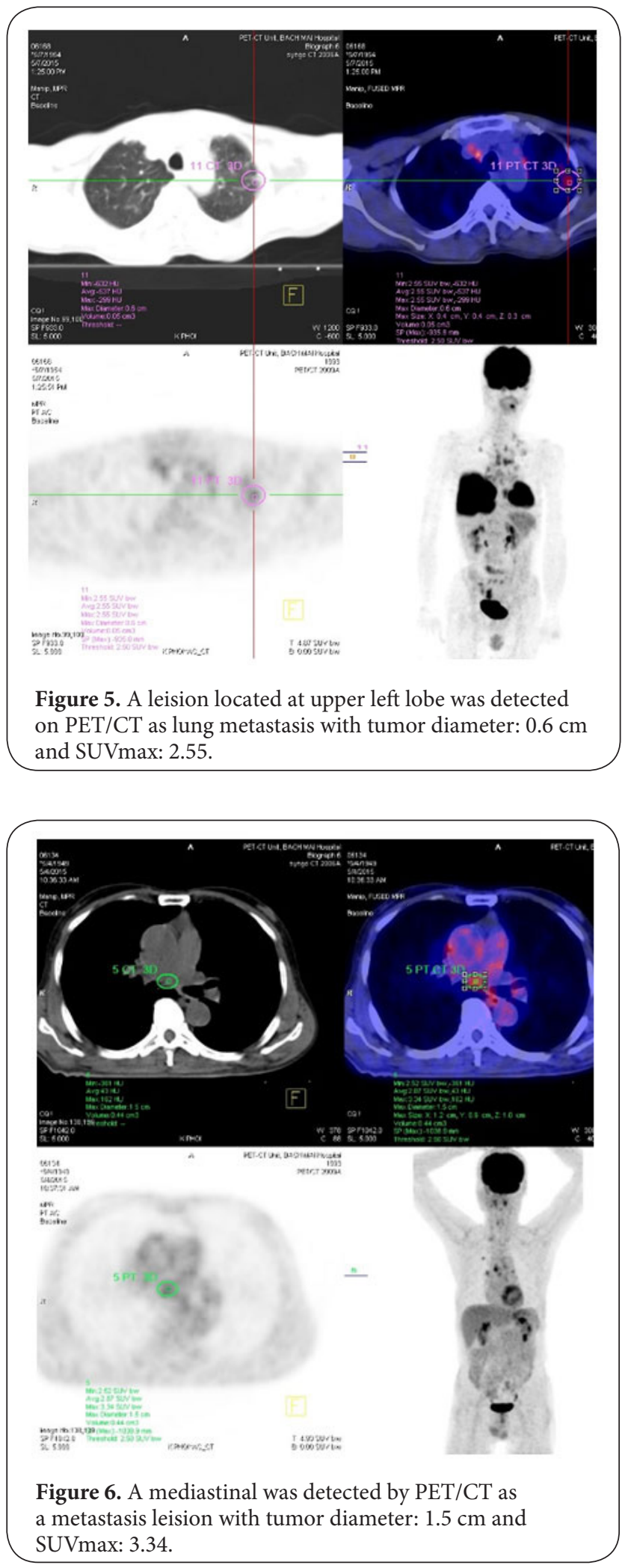

would develop drug resistance which is associated with the poor prognosis. Only $10-15 \%$ of patients with limited disease

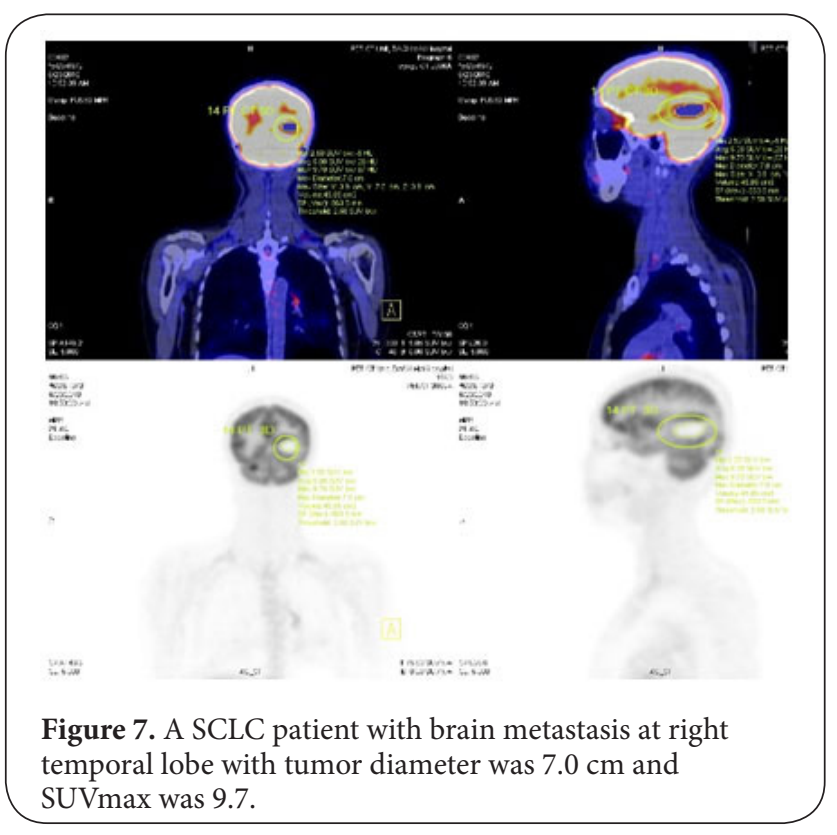

Table 2. Multivariate Logistic Resession.

\begin{tabular}{ll}
\hline Factor & P value \\
\hline Sex & 0.517 \\
Age & 0.162 \\
Stage & 0.429 \\
Pretreatment SUV & 0.001 \\
\hline
\end{tabular}

are still alive 2 years after diagnosis, while the overall survival (OS) of patients with extensive disease is even shorter $[\mathbf{1 9 , 2 0 ]}$. All of patients in our study were at stage III and IV, so the survival time was within 36 months after first performing PET/CT. The mean of survival time was 12.6 months ( $95 \% \mathrm{Cl}$ : $9.5-15.5$ months). Only one case survived up to 36 months (3.1\%).

Although $\mathrm{CT}$ or magnetic resonance imaging (MRI) provides precise anatomical and morphological information, the role of FDG-PET-CT has increased for diagnosis and staging of lung cancer [21]. Recently, FDG uptake has been reported to be a prognostic factor in patients with lung cancer [21-23]. Patz et al. [24] demonstrated that patients with positive FDG-PET-CT results, after treatment for lung cancer, had a significantly worse prognosis than patients with negative results.

The goal of our study was to understand the ability of PETCT scan to predict overall outcomes. Our results show that PET-CT scan can in fact act as a prognosticator for long-term survival. There are many different aspects of PET-CT scan that were reviewed in this study. Overall PET stage was seen to predict survival in our study. This finding has been seen previously [25] and is in part related to the poor overall outcome in patients identified with advanced disease, especially in patients with $\mathrm{M} 1$ disease [26].

Because patients with $\mathrm{M} 1$ disease have such guarded outcomes, 
we performed separate analyses of the role of SUV versus survival excluding these patients. Even after excluding patients with $\mathrm{M} 1$ disease, there was still a significant correlation between SUV and survival. Importantly, these analyses were performed adjusting for mass size to prevent potential confounding from a variable already known to be associated with worse survival. These findings are important in that they can perhaps guide treatment plan based on these values, as the SUV levels are known pretreatment.

We also thought it was important to analyze the correlation of SUV with survival within each clinical stage. But it is not significant in this study because of small sample size.

Our study has shown that survival decreases as SUV of the primary tumor increases. An important point that remains to be discovered, however, is the mechanism of failure in these patients. One potential mechanism is that tumors with higher SUV values have a more advanced stage at surgery than predicted by the pretreatment PET stage, implying that as the SUV increases, accuracy decreases. Another potential mechanism is earlier local recurrence of disease, implying that tumors with higher SUV values are more locally aggressive. Yet another possible mechanism is an increased propensity for distant metastasis. Prospective studies are required to determine the absolute causes for decreased survival in patients with higher SUV values.

Although we believe that SUV should be used as a gradient, we attempted to find a cutoff value, above and below which there were significant differences in survival. We were able to achieve this for SUVmax, with values of 9.16. We believe that these cutoff points can be useful as a reference for clinicians, and may eventually be able to be incorporated into a staging system. Further prospective studies are required, however, before this goal can be achieved. This cutoff would be especially practical in patients with no evidence of mediastinal disease pretreatment. Better ability to stratify these patients would lead to more accurate prediction of long-term outcome and more appropriate treatment preoperatively. Our results argue that patients with a high SUV would potentially profit from a more aggressive treatment plan, including mediastinoscopy before resection of the primary tumor and adjuvant chemotherapy, regardless of final pathologic results.

Many studies were on prediction of survival or treatment outcome in patients with NSCLC, while we found one report of those in SCLC using quantitative ${ }^{18} \mathrm{~F}-\mathrm{FDG}$ PET/CT [27]. According this report, 51 patients were progressive or recurrent with the median 6.9 months of progression free survival (PFS); and 50 patients were died with the median 11.7 months of overall survival (OS). Univariate analysis showed that MTVsum, TLGsum, number of lesions, live metastasis, bone metastasis, the cycle of chemotherapy and thoracic radiation therapy were all associated with PFS and OS (all $P<0.05$ ). Multivariate analysis demonstrated that live metastasis, the cycle of chemotherapy, MTVsum, TLGsum were the independent predictors of PFS (all $P<0.05$ ); and TLG sum were the independent predictors of OS (all $P<0.05$ ). SCLC is a subtype of lung cancer associated with dismal prognosis. The $7^{\text {th }}$ TNM classification and VALSG staging system are the most widely used models to predict the clinical outcome of SCLC currently [28].

This study has some limitations because of the small sample size and all patients were at stage III and IV. Further studies with larger patient groups and/ or early stage SCLC (stage I and II) included as controlsare needed to assess the relationship between primary tumor SUVmax and overall and diseasefree survival in patients with SCLC.

\section{Conclusion}

In conclusion, the prediction of patients with stage III and IV SCLC is very poor. A pretreatment SUV $_{\text {max }}$ of $\geq 9.16$ exhibited a worse OS compared with those with an SUV ${ }_{\max }$ of $<9.16$ in SCLC patients. These results indicate that pretreatment $S U V_{\text {max }}$ is a prognostic marker that could be used to identify high-risk patients with SCLC. Additional studies are warranted to determine if pretreatment SUV ${ }_{\text {max }}$ is associated with long-term prognosis.

\section{List of abrreviation}

${ }^{18}$ FDG PET-CT: [18F] fluoro-D-glucose positron-emission tomography

SCLC: Small cell lung cancer

CCRT: concurrent chemoradiotherapy

SUVmax: maximum standardized uptake value

TLG: Total Lesion Glycolysis

MTV: Metabolic tumor volume

OS: overall survival

PFS: Progression-free survival

TNM: Tumour Node Metastasis

VALSG: Veterans Administration Lung Study Group

\section{Competing interests}

The authors declare that they have no competing interests.

\section{Acknowledgments}

The author are grateful to physicians, administrative staff at HCMC Oncology Hospital for allowing us to undertake this research.

\section{Publication history}

Senior Editor: Domenico Rubello, Santa Maria della Misericordia Hospital, Italy.

Received: 26-May-2019 Final Revised: 18-Jun-2019

Accepted: 21-Jun-2019 Published: 09-Jul-2019

\section{References}

1. Barta JA, Powell CA and Wisnivesky JP. Global Epidemiology of Lung Cancer. Ann Glob Health. 2019; 85. I Article I PubMed

2. Abdel-Rahman $O$. Changing epidemiology of elderly small cell lung cancer patients over the last $\mathbf{4 0}$ years; a SEER database analysis. Clin Respir J. 2018; 12:1093-1099. | Article | PubMed

3. Yu JB, Decker RH, Detterbeck FC and Wilson LD. Surveillance epidemiology and end results evaluation of the role of surgery for stage I small cell lung cancer. J Thorac Oncol. 2010; 5:215-9. | Article | PubMed

4. Zhang R, Li P, Li Q, Qiao Y, Xu T, Ruan P, Song Q and Fu Z. Radiotherapy 
Huynh Quang Huy, Medical Imaging and Radiology 2019,

improves the survival of patients with extensive-disease small-cell lung cancer: a propensity score matched analysis of Surveillance, Epidemiology, and End Results database. Cancer Manag Res. 2018; 10:6525-6535. | Article I PubMed Abstract | PubMed FullText

5. Baum RP, Hellwig $D$ and Mezzetti M. Position of nuclear medicine modalities in the diagnostic workup of cancer patients: lung cancer. $Q \mathrm{~J}$ Nucl Med Mol Imaging. 2004; 48:119-42. | Article | PubMed

6. Lardinois D, Weder W, Hany TF, Kamel EM, Korom S, Seifert B, von Schulthess GK and Steinert HC. Staging of non-small-cell lung cancer with integrated positron-emission tomography and computed tomography. N Engl J Med. 2003; 348:2500-7. | Article | PubMed

7. Chen HH, Chiu NT, Su WC, Guo HR and Lee BF. Prognostic value of wholebody total lesion glycolysis at pretreatment FDG PET/CT in non-small cell lung cancer. Radiology. 2012; 264:559-66. | Article | PubMed

8. Goodgame B, Pillot GA, Yang Z, Shriki J, Meyers BF, Zoole J, Gao F, Dehdashti F, Patterson A, Siegel BA and Govindan R. Prognostic value of preoperative positron emission tomography in resected stage I nonsmall cell lung cancer. J Thorac Oncol. 2008; 3:130-4. | Article | PubMed

9. Hellwig D, Baum RP and Kirsch C. FDG-PET, PET/CT and conventional nuclear medicine procedures in the evaluation of lung cancer: $a$ systematic review. Nuklearmedizin. 2009; 48:59-69. | PubMed

10. Vansteenkiste J, Fischer BM, Dooms C and Mortensen J. Positronemission tomography in prognostic and therapeutic assessment of lung cancer: systematic review. Lancet Oncol. 2004; 5:531-40. | Article | PubMed

11. Benz MR, Herrmann K, Walter F, Garon EB, Reckamp KL, Figlin R, Phelps ME, Weber WA, Czernin J and Allen-Auerbach MS. (18)F-FDG PET/CT for monitoring treatment responses to the epidermal growth factor receptor inhibitor erlotinib. J Nucl Med. 2011; 52:1684-1689. | Article | PubMed Abstract | PubMed FullText

12. Huang W, Zhou T, Ma L, Sun H, Gong H, Wang J, Yu J and Li B. Standard uptake value and metabolic tumor volume of (1)(8)F-FDG PET/CT predict short-term outcome early in the course of chemoradiotherapy in advanced non-small cell lung cancer. Eur J Nucl Med Mol Imaging. 2011; 38:1628-35. | Article | PubMed

13. Inal A, Kucukoner M, Kaplan MA, Urakci Z, Nas N, Guven M, Dostbil $Z$, Altindag $S$ and Isikdogan A. Is (18)F-FDG-PET/CT prognostic factor for survival in patients with small cell lung cancer? Single center experience. Rev Port Pneumol. 2013; 19:260-5. | Article | PubMed

14. Kohutek ZA, Wu AJ, Zhang Z, Foster A, Din SU, Yorke ED, Downey $R$, Rosenzweig KE, Weber WA and Rimner A. FDG-PET maximum standardized uptake value is prognostic for recurrence and survival after stereotactic body radiotherapy for non-small cell lung cancer. Lung Cancer. 2015; 89:115-20. | Article | PubMed Abstract | PubMed FullText

15. Lin Y, Lin WY, Kao CH, Yen KY, Chen SW and Yeh JJ. Prognostic value of preoperative metabolic tumor volumes on PET-CT in predicting disease-free survival of patients with stage I non-small cell lung cancer. Anticancer Res. 2012; 32:5087-91. | Article | PubMed

16. Mehta G, Chander A, Huang C, Kelly M and Fielding P. Feasibility study of FDG PET/CT-derived primary tumour glycolysis as a prognostic indicator of survival in patients with non-small-cell lung cancer. Clin Radiol. 2014; 69:268-74. | Article | PubMed

17. Chen KN. [Small Cell Lung Cancer and TNM Staging]. Zhongguo Fei Ai Za Zhi. 2016; 19:409-12. | Article | PubMed Abstract | PubMed FullText

18. Torre LA, Siegel RL and Jemal A. Lung Cancer Statistics. Adv Exp Med Biol. 2016; 893:1-19. | Article | PubMed

19. Janne PA, Freidlin B, Saxman S, Johnson DH, Livingston RB, Shepherd FA and Johnson BE. Twenty-five years of clinical research for patients with limited-stage small cell lung carcinoma in North America. Cancer. 2002; 95:1528-38. | Article | PubMed

20. Micke P, Faldum A, Metz T, Beeh KM, Bittinger F, Hengstler JG and Buhl R. Staging small cell lung cancer: Veterans Administration Lung Study Group versus International Association for the Study of Lung Cancer-what limits limited disease? Lung Cancer. 2002; 37:271-6. | Article | PubMed

21. Al-Sarraf N, Gately K, Lucey J, Aziz R, Doddakula K, Wilson L, McGovern $E$ and Young $V$. Clinical implication and prognostic significance of standardised uptake value of primary non-small cell lung cancer on positron emission tomography: analysis of $\mathbf{1 7 6}$ cases. Eur J Cardiothorac Surg. 2008; 34:892-7. | Article | PubMed

22. Dhital K, Saunders CA, Seed PT, O'Doherty MJ and Dussek J. [(18)F] Fluorodeoxyglucose positron emission tomography and its prognostic value in lung cancer. Eur J Cardiothorac Surg. 2000; 18:425-8. | Article | PubMed

23. Hanin FX, Lonneux M, Cornet J, Noirhomme P, Coulon C, Distexhe J and Poncelet AJ. Prognostic value of FDG uptake in early stage non-small cell lung cancer. Eur J Cardiothorac Surg. 2008; 33:819-23. | Article | PubMed

24. Patz EF, Jr., Connolly J and Herndon J. Prognostic value of thoracic FDG PET imaging after treatment for non-small cell lung cancer. AJR Am J Roentgenol. 2000; 174:769-74. | Article | PubMed

25. Cerfolio RJ, Bryant AS, Ohja B and Bartolucci AA. The maximum standardized uptake values on positron emission tomography of a nonsmall cell lung cancer predict stage, recurrence, and survival. J Thorac Cardiovasc Surg. 2005; 130:151-9. | Article | PubMed

26. Ginsberg MS, Grewal RK and Heelan RT. Lung cancer. Radiol Clin North Am. 2007; 45:21-43.

27. Ding CY, Guo Z, Li YY and Li TR. [Prognostic value of (18) F-fluorodeoxyglucose (FDG) positron emission tomography-computed tomography (PET-CT) in extensive-stage small cell lung cancer]. Zhonghua Zhong Liu Za Zhi. 2017; 39:828-834. | Article | PubMed

28. Pan H, Shi X, Xiao D, He J, Zhang Y, Liang W, Zhao Z, Guo Z, Zou X and Zhang J. Nomogram prediction for the survival of the patients with small cell lung cancer. J Thorac Dis. 2017; 9:507-518. | Article | PubMed Abstract | PubMed FullText

\section{Citation:}

Huy HQ. Prediction of overall survival in patients with stage III and IV small cell lung cancer utilizing Primary tumor standardized uptake value on 18F-FDG PET/CT. Med Imaging Radiol. 2019; 7:4.

http://dx.doi.org/10.7243/2054-1945-7-4 